\title{
EVALUATION OF SHEAR AND FLEXURAL DEFORMATIONS
}

\section{OF FLEXURAL TYPE SHEAR WALLS}

\author{
Hisahiro Hiraishi* \\ Presented at the Third South Pacific Regional Conference on \\ Earthquake Engineering, Wellington, May 1983.
}

\section{$\underline{\text { SYNOPSIS }}$}

In order to predict the inelastic response of reinforced concrete structures under dynamic earthquake loading, hysteretic behaviour of their structural components must be evaluated appropriately. Though various restoring force models have already been proposed for beams and columrs, hysteretic behaviour of flexural type shear walls remains unclear in many respects.

In this paper, an evaluation method of distributing the total deformation of a shear wall into the flexural and shear deformation is mentioned and an analytical one of evaluating these deformations is proposed. The comparison of analytical results with test results of shear walls is carried out.

\section{INTRODUCTION}

In order to predict the history of inelastic response of reinforced concrete structures under dynamic earthquake loading, hysteretic behaviour must be known for each seismic member, that is, beams, columns and shear walls. Hysteretic behaviour of beams and columns has been made clear through many experimental and analytical studies, and some hysteretic load versus deformation models, such as the Takeda model (which shows good agreement with experimental results of flexural members), have already been proposed. However, a proper practical hysteretic load versus deformation model for shear walls has not yet been proposed.

Many experimental studies on shear walls have been carried out, but most of their load-deformation data are presented in terms of the load versus total deformation. Very few data refer to the shear and flexural deformations primarily because of the difficulty in separating the total deformation into these two deformations.

This paper reports on an evaluation method of distributing the total deformation of a shear wall into the flexural and shear deformations. For this evaluation, rotation at the storey mid-height of a shear wall is used in addition to the horizontal and vertical displacements at four corners of a shear wall.

Furthermore, this paper describes analytical method of evaluating flexural and shear deformations of shear walls whose flexural reinforcing bars of boundary column under tension yield. In the analysis, such a shear wall is represented as a truss system having a non-prismatic truss member based on test results of shear walls conducted by US-Japan Cooperative Seismic Research Program. This paper also proposes an hysteretic model of each component of deformation.

*Senior Research Engineer of Structure Division, Building Research Institute, Ministry of Construction, Japanese Government.

BULLETIN OF THE NEW ZEALAND NATIONAL SOCIETY FOR EARTHOUAKE ENGINEERING, VOL. 17, NO. 2, JUNE 1984
In shear wall tests, shear deformation is sometimes conventionally estimates from changes in the length of the two diagonals. However, the shear deformation given by this method contains flexural deformation because of the existence of a moment gradient along the height of shear walls.

This chapter describes the relationship between horizontal and vertical displacements at the four corners of a shear wall, and the relationships between flexural deformation, shear deformation, and expansion. It also proposes a simple method to evaluate each deformation.

\section{Components of Deformation}

Displacements of a shear wall subjected to a lateral load are illustrated in Figure 1. With an aim towards simplification of the development of equations, horizontal and vertical displacements at the base are modified to be zero. It is also assumed that these displacements can be represented by three components, that is, shear deformation (which includes slip), flexural deformation, and expansion. The sign for horizontal and vertical displacements is positive in the upper and right hand side directions and elongation is positive for diagonal displacements. The following relations are assumed:

$$
\begin{aligned}
& u_{L S}=u_{R S}=u_{S} \\
& u_{R E}=-u_{L E}=u_{E} \\
& u_{L B}=u_{R B}=u_{B} \\
& v_{R E}=-v_{L E}=v_{E}
\end{aligned}
$$

There are relationships between these displacements and those shown in Figure 1 as follows :

$$
\begin{aligned}
& u_{R}=u_{S}+u_{E}+u_{B} \\
& u_{L}=u_{S}-u_{E}+u_{B}
\end{aligned}
$$




$$
\begin{aligned}
& v_{R}=v_{E}+v_{R B} \\
& v_{L}=v_{E}+v_{L B} \\
& \delta_{I}-\delta_{2}=\delta_{1 S}+\delta_{1 B}-\left(\delta_{2 S}+\delta_{2 B}\right) \\
& =\frac{\ell}{d}\left(u_{R}+u_{L}\right)+\frac{h}{d}\left(v_{R}-v_{L}\right) \\
& =\frac{2 \ell}{d}\left(u_{S}+u_{B}\right)+\frac{h}{d}\left(v_{R}-v_{L}\right)
\end{aligned}
$$

From equations (5) and (6), horizontal displacement due to expansion and the total of flexural and shear deformations can be given by equations (10) and (11), respectively, in terms of nodal horizontal displacements.

$$
\begin{aligned}
& u_{E}=\frac{1}{2}\left(u_{R}-u_{L}\right) \\
& u_{S}+u_{B}=\frac{1}{2}\left(u_{R}+u_{L}\right)
\end{aligned}
$$

Equation (11) indicates that the deformation of the hysteretic load versus deformation relationship which is used in dynamic response analysis must be expressed not by each nodal horizontal displacement but by their average value.

Thus, the shear deformation can be given by equation (12) from equation (9).

$$
\begin{aligned}
\mathrm{u}_{\mathrm{S}} & =\frac{\mathrm{d}}{2 l}\left(\delta_{1}-\delta_{2}\right)-\left\{\mathrm{u}_{\mathrm{B}}+\frac{\mathrm{h}}{2 l}\left(\mathrm{v}_{\mathrm{R}}-\mathrm{v}_{\mathrm{L}}\right)\right\} \\
& =\frac{\mathrm{d}}{2 l}\left(\delta_{1}-\delta_{2}\right)-\left(\mathrm{u}_{\mathrm{B}}-\frac{\mathrm{h}}{2} \theta\right)
\end{aligned}
$$

where,

$$
\theta=\frac{1}{l}\left(v_{L}-v_{R}\right)=\frac{1}{l}\left(v_{L B}-v_{R B}\right)
$$

he shear deformation is also given by equation (14) from equation (11) in a different expression:

$$
\mathrm{u}_{\mathrm{S}}=\frac{1}{2}\left(\mathrm{u}_{\mathrm{R}}+\mathrm{u}_{\mathrm{L}}\right)-\mathrm{u}_{\mathrm{B}}
$$

Expression of Flexural Deformation and Shear Deformation in Terms of Rotation

Equations (12) and (14) imply that in order for shear deformation to be estimated, flexural deformation must inevitably be estimated with sufficient accuracy. Flexural deformation can be assumed to be given by equation (15):

$$
\mathrm{u}_{\mathrm{B}}=\int_{0}^{\mathrm{h}} \theta_{\mathrm{y}} \mathrm{dy}=\int_{0}^{\mathrm{h}} \frac{1}{\ell}\left(\mathrm{v}_{L Y}-\mathrm{v}_{\mathrm{RY}}\right) \mathrm{dy}
$$

In equation (15), $\theta, v_{L Y}$ and $v_{R Y}$ represent the rotation of a shear wall and the vertical displacements of right-hand side and left-hand side boundary columns at $y$ in the y direction, respectively. An example of the distribution of $\theta$ along the height of a cantilever shear wall is illustrated in Figure 3. Curvature is dramatically increased around the base where the occurrence of cracks and yielding of steel is usually observed.

Equation (15) can be rewritten by equation (17) using a new factor $\alpha$. defined by equation (16):

$$
\alpha=\frac{\int_{0}^{h} y d y}{\theta h}
$$

$$
u_{B}=\alpha \theta h
$$

$\alpha$ is the ratio of the shaded area to that surrounded by solid lines $A B C D$ in Figure 3. Therefore, it is reduced to the prediction of this ratio to evaluate flexural deformation. With regard to $\alpha$, there is generally a relationship as shown in equation (18), when the point of contraflexure is located above the subject storey of a shear wall.

$$
1 / 2<\alpha<1
$$

By substituting equation (17) into equation (12) or equation (14), shear deformation is given as follows:

$$
\begin{aligned}
\mathrm{u}_{\mathrm{S}} & =\frac{\mathrm{d}}{2 l}\left(\delta_{1}-\delta_{2}\right)-\left(\alpha-\frac{1}{2}\right) \theta \mathrm{h} \\
\text { or } \mathrm{u}_{\mathrm{S}} & =\frac{1}{2}\left(\mathrm{u}_{\mathrm{R}}+\mathrm{u}_{\mathrm{L}}\right)-\alpha \theta \mathrm{h}
\end{aligned}
$$

Equation (19) proves that shear deformation given approximately by only changes in the length of diagonals, corresponds to shear deformation given by $1 / 2$ of $\alpha$. However, if $1 / 2$ of $\alpha$ is assumed, the shaded area in Figure 3 would be approximately represented by the area of the triangle $A B C$, which occurs only in the case of pure bending, and this therefore results in an overestimation of shear deformation.

Figure 3 is nothing but a conceptual illustration, but it does not seem to be difficult to evaluate $\alpha$ with certain accuracy because of the general behaviour of rotation. For example, if either rotation $\theta_{M}$, or right-hand side and left-hand side vertical displacements at mid-height of the subject storey of a shear wall were measured, considerable improvement of accuracy in evaluation of $\alpha$ could be expected as follows: in Figure 4, case 1 shows the case where rotation distribution is represented by the lines connecting the measured point $M$ and points $A$ and $C$, whereas case 2 shows the case where that is represented by the line connecting $\theta_{M} / 2$ and $\left(\theta+\theta_{M}\right) / 2$ whose tangent is equal to that of the line connecting points $\mathrm{A}$ and $\mathrm{C}$ and by the lines connecting both ends and points $A$ and $C$. The ratios $\alpha_{1}$ and $\alpha_{2}$ of the area surrounded by these approximate lines to the area ABCD are given by equations (21) and (22), respectively. There is generally relationships given by equations (23) and (24) between approximate values $\alpha_{1}$ and $\alpha_{2}$ and the exact value $\alpha$

$$
\begin{aligned}
& \alpha_{1}=\frac{1}{2}\left(0.5+\frac{\theta_{M}}{\theta}\right) \\
& \alpha_{2}=\frac{1}{4}\left(0.5+3 \frac{\theta_{M}}{\theta}\right) \\
& 0.75<\alpha_{1} / \alpha<1 \\
& 0.875<\alpha_{2} / \alpha<1.167
\end{aligned}
$$

The maximum possible error amounts to 25 percent for $\alpha_{1}$ and 16.7 percent for $\alpha_{2}$. However, $\alpha_{2}$ seems to estimate $\alpha$ with good accuracy as is expected from equation (24) and Figure 4, and the excellent accuracy of $\alpha_{2}$ was proved through nonlinear analytical case studies on single and seven storey shear walls. 


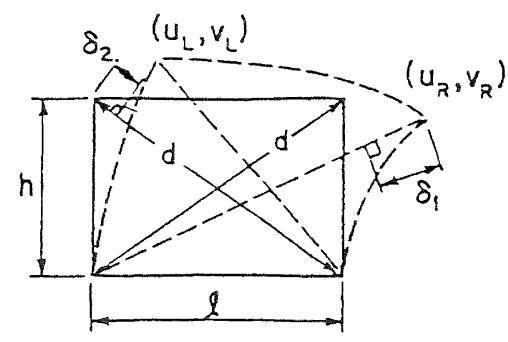

Fig. I Deformation of Shear Wall Subjected to Lateral Ioad

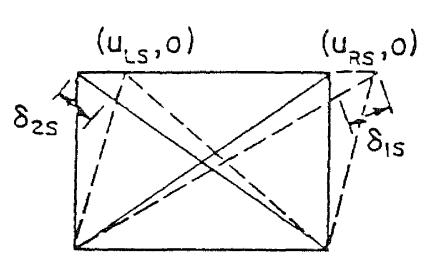

Shear

Deformation

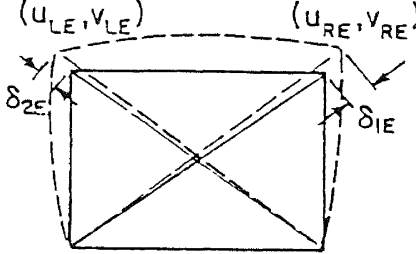

Expansion

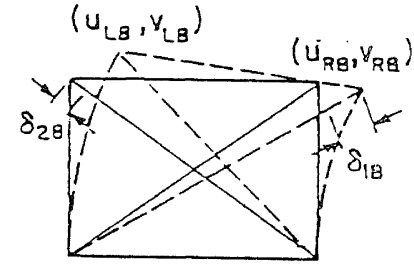

Flexural Deformotion

Fig. 2 Components of Deformation
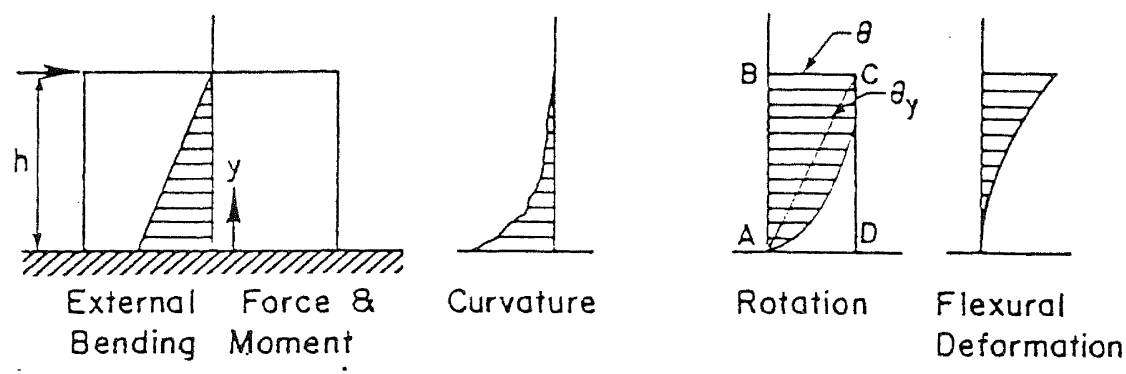

Fig. 3 Distribution of Rotation of a Cantilever Type Shear Wall (Pull out of Steel at Base is Neglected)

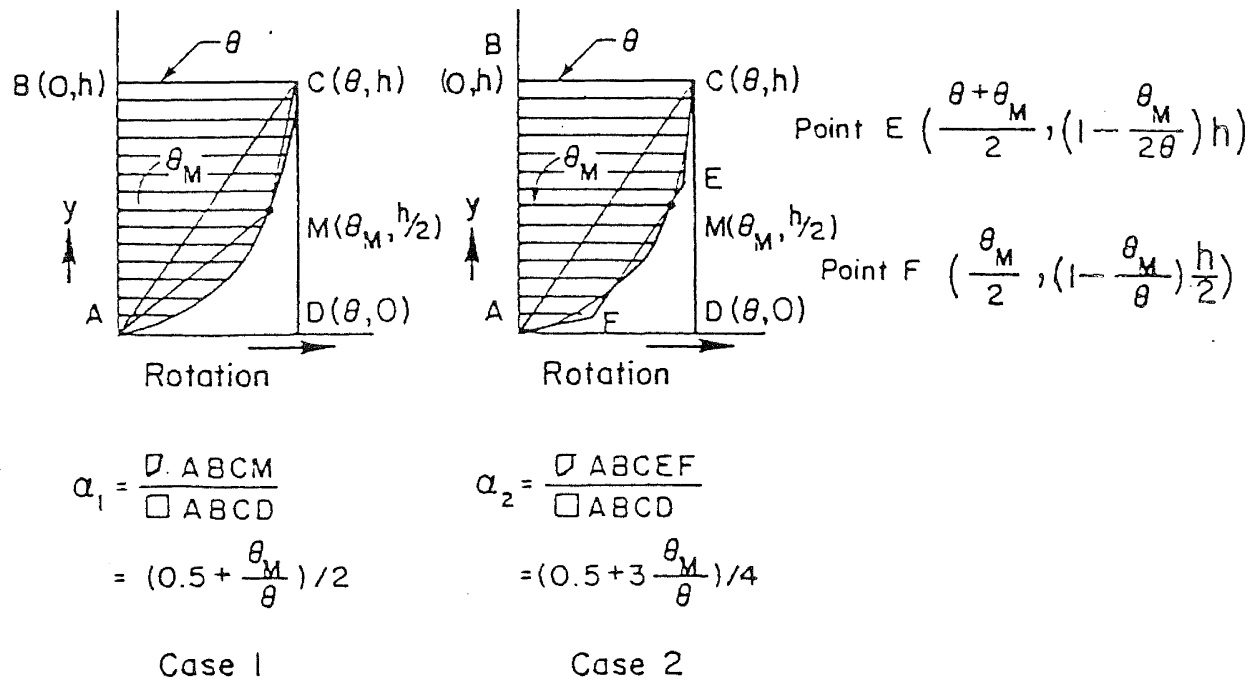

Fig. 4 Methods of Estimation for $\alpha$ 
RELATIONSHIPS BETWEEN SHEAR AND FLEXURAL DEFORMATIONS OF FLEXURAL TYPE SHEAR WALLS

When reinforcing bars of a boundary column under tension yield, cracks developed in the tension side column extending obliquely to the bottom part of the compression side column through in-filled panel wall. As a result, both the shear and flexural deformations increase significantly (1). After these cracks take place, the hypothesis of a plane section remaining plane is no longer suitable. H Bachmann already reported experimental results that hinging region of beams increased according to development of shear cracks, and also presented its analytical proof based on the stress of flexural reinforcing bars under tension given by equilibrium of forces at an inclined cracked surface (2).

In this chapter, the stress of flexural reinforcing bars of boundary column under tension is expressed by H Bachmann's theory. The shear wall is represented as a truss system having a non-prismatic truss member whose cross-sectional area is determined by the stress along the height of boundary column. Then flexural and shear deformations are evaluated.

Stress of Reinforcing Bars of Boundary Column Under Tension

Figures 5 and 6 show crack patterns of three shear walls tested in US-Japan Cooperative Research Program. Figure 7 shows forces and moment at an inclined cracked surface which is modified based on Figures 5 and 6 , and those at the base. In these figures, the following new notations are used:

$\mathrm{T}_{n}=$ resultant tensile force of reinforcing bars of boundary column under tension at $y$ height.

$\mathrm{T}_{0}=$ resultant tensile force of reinforcing bars of boundary column under tension at the base

$\mathrm{T}_{\mathrm{W}}=$ resultant tensile force of vertical reinforcing bars, across an inclined cracked surface, of the in-filled panel wall

$\mathrm{T}_{\mathrm{w0}}=$ resultant tensile force of vertical reinforcing bars of the in-filled panel wall at the base

$\mathrm{Q}_{\mathrm{W}}=$ lateral force acting on the shear wall

$Q_{C}=$ shear force of boundary column under compression at an inclined cracked surface

$C_{c}=$ axial force of boundary column under compression at an inclined cracked surface

$\mathrm{M}_{0}=$ moment at the base

$\mathrm{N}$ = axial force of the shear wall

$n=y / h$

Assuming that $T_{W}, Q_{W}$ acting on an inclined surface are ${ }^{W}$ concentrated at $\ell / 2$ and $\eta h / 2$, respectively, the resultant tensile force $\mathrm{T}_{n}$ of the boundary column under tension is given by equation (26).

$$
\mathrm{T}_{n}=\frac{1}{\ell}\left(\mathrm{M}_{0}-\mathrm{T}_{\mathrm{w}} \frac{\ell}{2}-\mathrm{Q}_{\mathrm{w}} \frac{\eta \mathrm{h}}{2}-\frac{\mathrm{N} \ell}{2}\right)
$$

Assuming that $\mathrm{T}$ at the base is concentrated at $\ell / 2$, equation (27) is obtained:

$$
\mathrm{M}_{0}=\mathrm{T}_{0} \ell+\mathrm{T}_{\mathrm{w} 0} \frac{\ell}{2}+\frac{\mathrm{N} \ell}{2}
$$

Substituting equation (27) into equation (26), and assuming equations (28) and (29) equation (31) is obtained

$$
\begin{aligned}
& \mathrm{T}_{\mathrm{w}}=\mathrm{T}_{\mathrm{w} 0} \\
& \mathrm{Q}_{\mathrm{w}}=\mathrm{a}_{\mathrm{w}} \sigma_{\mathrm{y}} n
\end{aligned}
$$

where,

$$
a_{w}=P_{h} t h
$$

$\mathrm{P}_{\mathrm{h}}=$ ratio of vertical reinforcement area to the gross concrete area of a horizontal section of the in-filled panel wall

$\mathrm{t}=$ wall thickness

$\mathrm{Q}_{\mathrm{y}}=\underset{\text { bar }}{\text { tensile }}$

$$
T_{\eta}=T_{0}-\frac{a_{w} h}{2 l} \sigma_{y} n^{2}
$$

The stress of reinforcing bars of the boundary column under tension of $y$ height is given by equation (32).

$$
\sigma_{n}=\frac{T_{n}}{a_{t}}=\sigma_{0}-r \sigma_{y} n^{2}
$$

where,

$a_{t}=$ sum of the cross-sectional area of reinforcing bars of the boundary column under tension

$\sigma_{0}=$ stress of reinforcing bars of the boundary column under tension at the base

$\sigma_{n}=$ stress of reinforcing bars of the boundary column under tension at $y$ height

$$
r=\frac{a_{w} h}{2 a_{t} l}
$$

The analysis is not applied to the region where stress given by equation (32) is much less than that given by assuming a plane section remaining plane.

\section{Truss Model of Shear Walls}

Shear walls after yielding of flexural reinforcing bars of the boundary column under tension is expressed as a truss model shown in Figure 8 . In this paper, the main object of the analysis is placed to deformations at the first storey, so truss members above the first storey are assumed to be rigid. It is also assumed that shortening of the boundary column under compression is negligible, and tensile chord member (boundary column under tension) is expressed as a non-prismatic member whose crosssectional area is given by equation (34) so as for existing stress to satisfy 

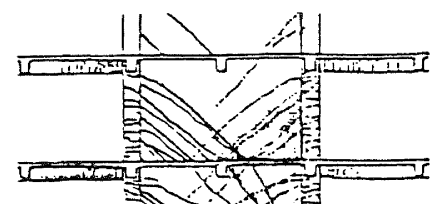

Fig. 5 Crack Pattern of Lower Three Story Shear Wall of a FullScale Seven Story Structure Test ${ }^{3)}$ at Tip Drift Angle of $1 / 64$

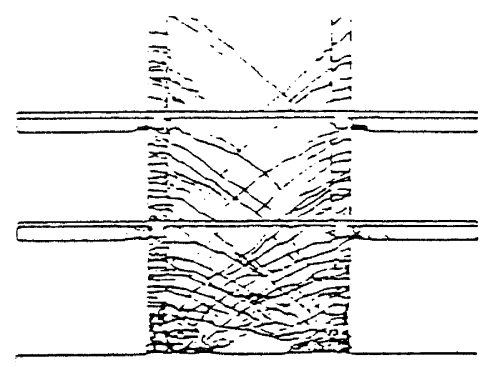

Specimen $\mathrm{W} 1$

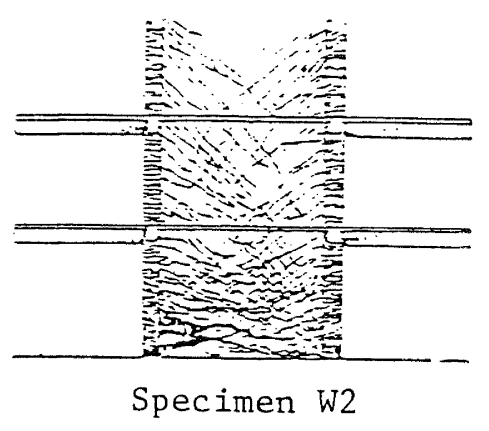

-Fig. 6 Final Crack Pattern of Half-Scale Three Story Shear Wall Tests ${ }^{4)}$
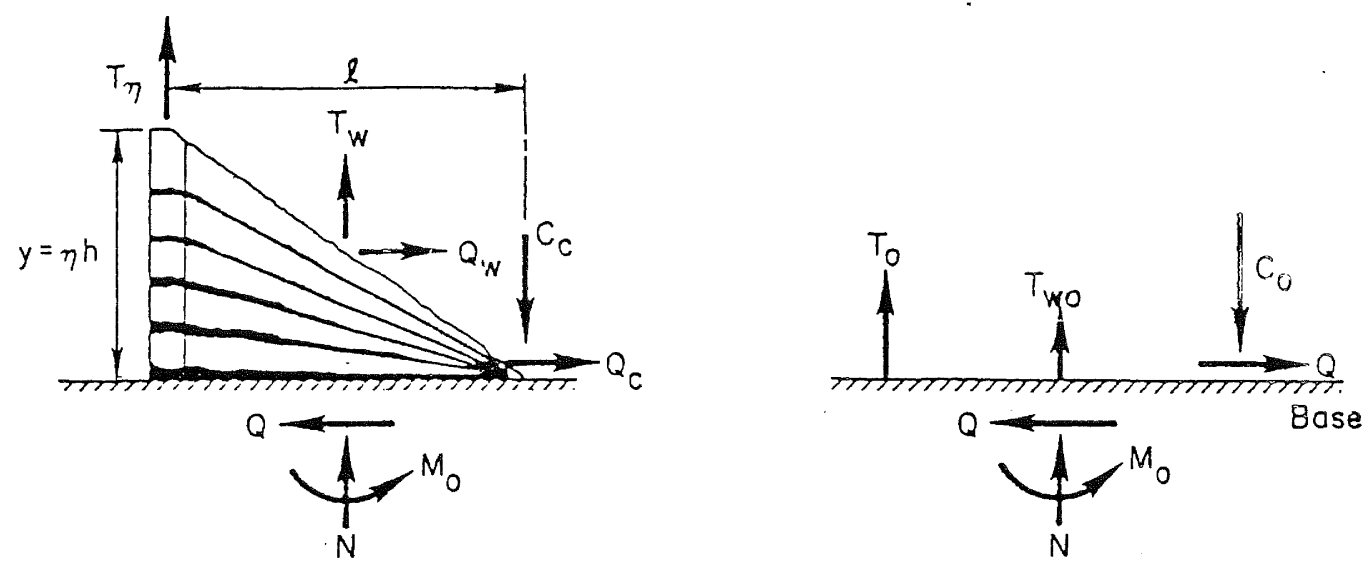

Fig. 7 Forces and Moment at a Cracked Surface and at the Base
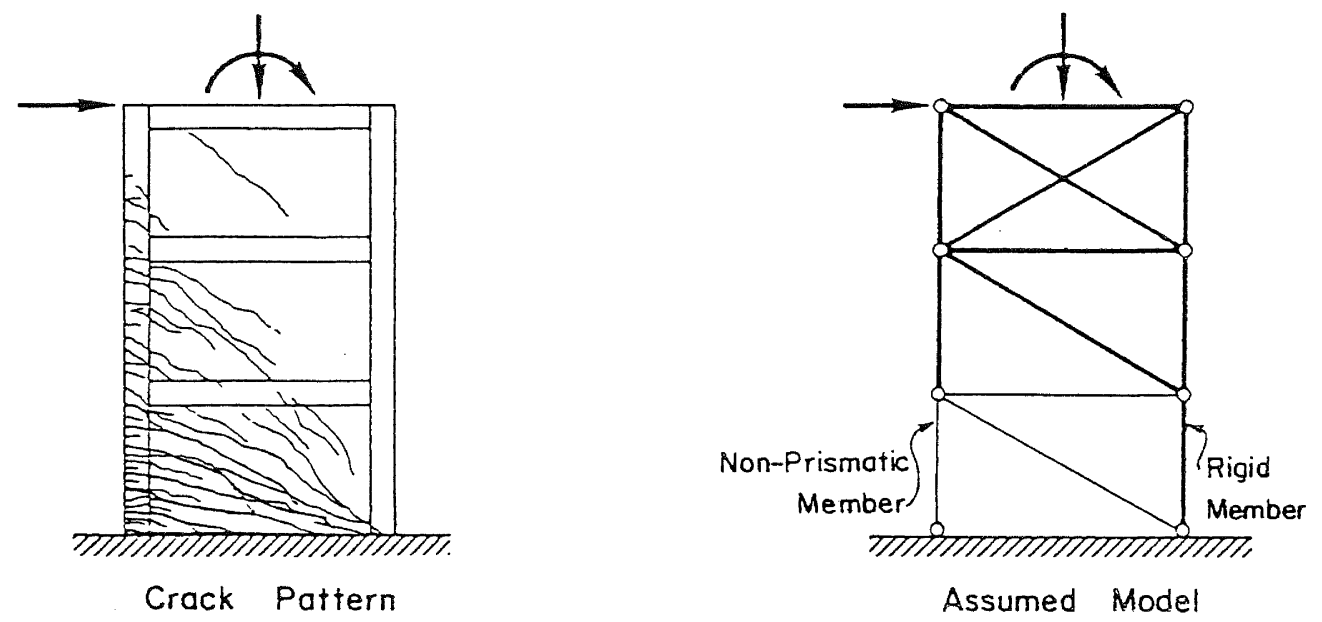

Fig. 8 Assumed Truss Model 
equation (32).

$$
A_{n}=\frac{\sigma_{0}}{\sigma_{\eta}} A_{0}=\frac{\sigma_{0}}{\sigma_{0}-r \sigma_{y} n^{2}} A_{0}
$$

where,

$A_{n}=a$ cross-sectional area of the tensile chord member, at y height, of the assumed truss system

$A_{0}=a$ cross-sectional area of the tensile chord member, at the base, of the assumed truss system.

The deformation of this truss system consists of deformation due to stretching of the tension side column, that due to shortening of the diagonal compression member, and that due to stretching of the beam (horizontal tensile member). Figures 9 and 10 show their components. There are following relationships between these components.

$$
\begin{aligned}
& u_{1}=u_{s}+u_{B}=u_{1}+u_{2}+u_{3} / 2 \\
& u_{1}=u_{B}+u_{s 1}=\theta h \\
& u_{2}=u_{s 2}=\frac{d}{l} \delta \\
& u_{3}=2 u_{s 3}=2 u_{E} \\
& u_{B}=\alpha \theta h=\alpha u_{1} \\
& u_{s}=u_{s 1}+u_{s 2}+u_{s 3} \\
& u_{s 1}=(1-\alpha) \theta h=(1-\alpha) u_{1}=\left(\frac{1}{\alpha}-1\right) u_{B} \\
& \theta=v / l \\
& \theta_{\eta}=v_{\eta} / \ell
\end{aligned}
$$

where,

$u=$ average horizontal displacement of the right-hand side and left-hand side horizontal displacements of the first storey (sum of flexural and shear deformations)

$u_{1}=$ tip horizontal displacement due to stretching of the tension side column

$\mathrm{u}_{2}=$ tip horizontal displacement due to shortening of the diagonal compression member

$\mathrm{u}_{3}=$ right-hand side tip horizontal displacement due to stretching of the beam

$u_{s 1}, u_{2}, u_{2}=$ shear deformation due to stretcking of the tension side column, that due to shortening of the diagonal compression member, and that due to stretching of the beam, respectively

$\theta_{\eta}=$ rotation at $\mathrm{y}$ height

$\mathrm{v}=$ vertical tip displacement of the tension side column $v_{n}=$ vertical displacement of the tension side column at y height

It is clear from equation (41) and Figure 10 that the shear deformation $u$ increases according to increase in tips rotation (flexural deformation), because of the general condition: $1 / 2<\alpha<1$.

Figure 11 shows the envelope curves of load versus deformation relationships, during positive loading, of the first storey of the shear wall tested in PCA in the US-Japan Cooperative Research Program (5). The vertical displacement of the column under compression is little amount as it is assumed in the analysis, and the sum of the displacements $u_{s}$ and $u_{s} 3$ is small enough. In the case of such small displacements of $u_{s}$ and $u_{s}$ as this, there must be the relationship of $u / h=\theta$ according to the truss model shown in Figures 8-10. This relationship is obviously observed in the test result shown in Figure 12. The similar results for this relationship also seem to be found in the test results of the nine flexural type shear walls reported by Mr R G Oesterle et al in 1976 (1).

Consequently, in order to evaluate deformations of flexural type shear walls, the truss model proposed in this paper seems to be a suitable representation. Furthermore, as the deformations of $u_{s} 2$ and $u_{3}$ are little amount as shown in Figure 11, the dramatical increase in shear deformation after yielding is explained not by deterioration of shear rigidity due to flexural cracks, which have been pointed out by $V \mathrm{~V}$ Bertero and $\mathrm{R} G$ Oesterle, but by a rotation mechanism having rotation origin at the base of the column under compression.

Vertical Displacement of the Boundary Column Under Tension and Flexural Deformation

Vertical displacement $\mathrm{v}$ of the boundary column under tension is given by equation (44), and flexural deformation $u_{B}$ and $\alpha$ are given by equation (45) and (46).

$$
\begin{aligned}
\mathrm{v} & =\mathrm{h} \int_{0}^{1} \varepsilon_{n} \mathrm{~d} n \\
\mathrm{u}_{\mathrm{B}} & =\mathrm{h} \int_{0}^{1} \theta_{n} \mathrm{~d} n \\
& =\frac{\mathrm{h}}{\ell} \int_{0}^{1} \mathrm{v}_{n} \mathrm{~d} n \\
& =\frac{h^{2}}{\ell} \int_{0}^{1} \int_{0}^{n} \varepsilon_{n} \mathrm{~d} n \mathrm{~d} n \\
\alpha & =\frac{\mathrm{u}_{\mathrm{B}} l}{\mathrm{vh}}
\end{aligned}
$$

where,

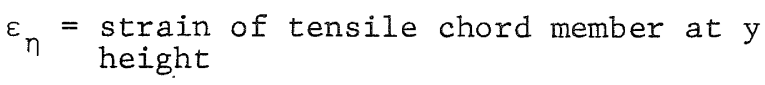

The stress of tensile chord member at $y$ height is determined based on the existing stress which is given by equation (32). 


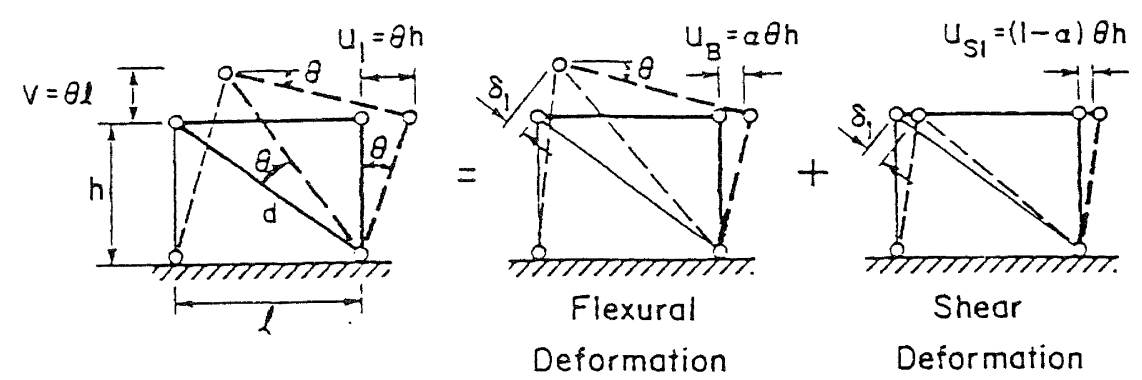

Deformation due to Stretching of Tension Side Column
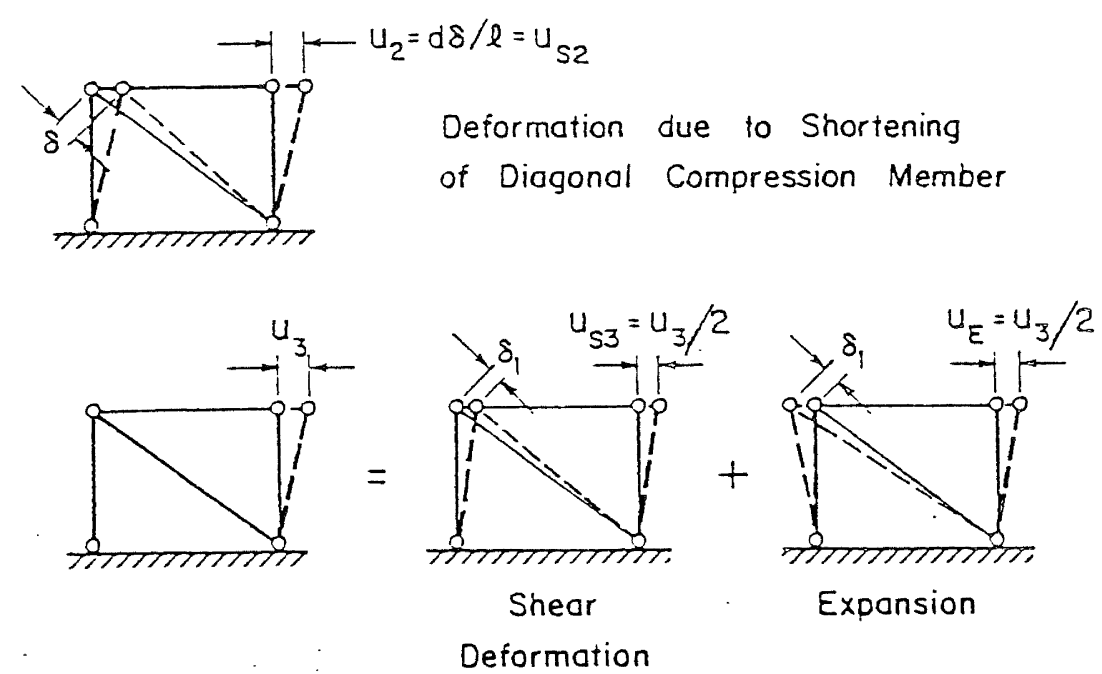

Deformation due to Stretching of Beam

Fig. 9 Deformations due to Stretching and Shortening of Each Truss Member

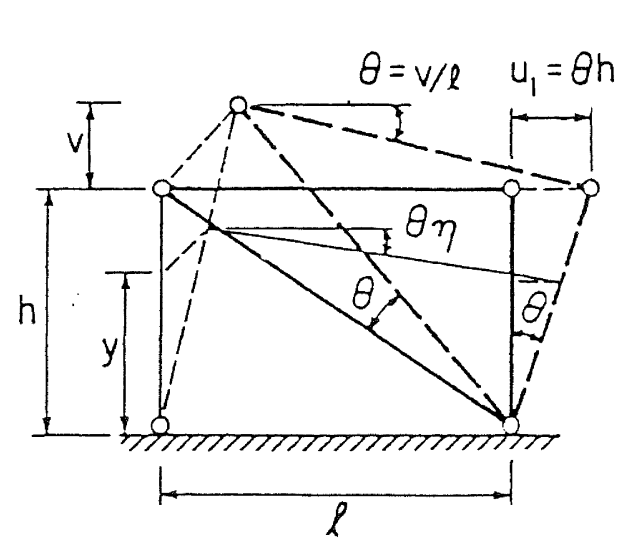

Deformation

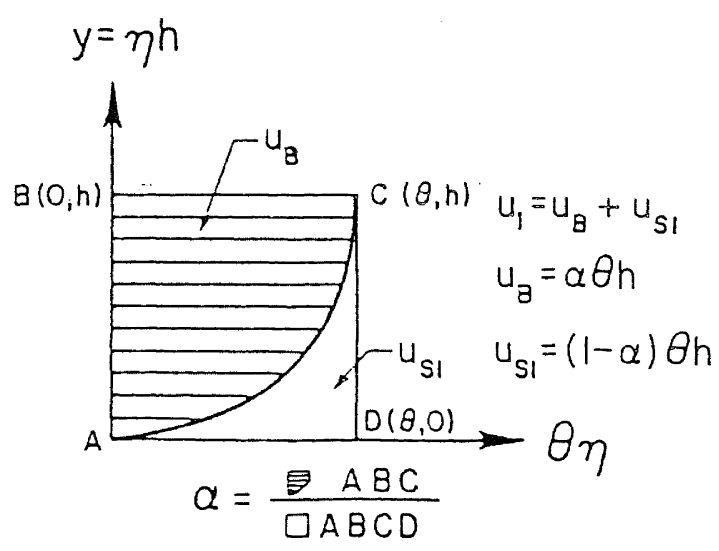

Distribution of Rotation

Fig. 10 Relationship of Rotation versus Flexural and Shear Deformations of $u_{1}$ 


\section{Numerical Examples}

Figures 14 and 15 show the case study of flexural type shear walls where the ratio of the amount of horizontal reinforcement in the wall to the total sectional area of flexural reinforcing bars of the boundary column under tension is parametrically changed. The stress versus strain relationship for reinforcing bars of the tension side column is represented as shown in Figure 13. The aspect ratio of the first storey height to width between centres of boundary columns, and material constants for steel are assumed as follows:

$$
\begin{aligned}
& \mathrm{h} / \mathrm{l}=3.5 \mathrm{~m} / 6 \mathrm{~m}=0.583 \\
& \mathrm{E}_{\mathrm{S}} / \mathrm{E}_{\mathrm{sH}}=75, \varepsilon_{\mathrm{sH}} / \varepsilon_{\mathrm{y}}=10
\end{aligned}
$$

$u_{B}$ and $u_{s}$ increase according to tip drift angle. In the large deformation region, $u_{S l}$ is nearly equal to $u_{B}$ when $a_{W} / a_{t}$ is small, and $u_{s l}$ is a fairly large amount even when $a_{w} / a_{t}$ is large. It is found, from Figure 15, that $\alpha$ has the maximum value when $u_{1} / h \cong 1 / 400$, then it gradually decreases, and it converges into some constant value after yielding of flexural reinforcing bars of the boundary column under tension at top of the first storey. The symbol $o$ in Figures 14 and 15 means this condition.

\section{HYSTERETIC MODEL OF THE LOAD VERSUS}

\section{DEFORMATION RELATIONSHIP}

This chapter proposes a hysteretic model of the load versus deformation relationships of the first storey for flexural type shear walls. In this model, the relationships derived in preceding sections are taken into consideration. A sufficient test data has not been presented even for the load versus flexural deformation relationship. The proposed hysteretic model is, therefore, nothing but an idea. Further studies are highly recommended.

Primary Curve of the Load Versus Deformation Relationship

The primary curve for the load versus flexural deformation relationship has three breaking points as shown in Figure 16. These breaking points are flexural cracking, yielding and maximum strengths.

The primary curve for the load versus shear deformation relationship before yielding is represented by bilinear, and that after yielding in flexure is done by a curved line which is given by equation (47) by considering the $u_{\text {versus }} u_{B}$ relationship shown in equation (41), ${ }^{B}$ and $u_{s 2}$ and $u_{s 3}$.

$$
\begin{aligned}
u_{s} & =u_{s 1}+u_{s 2}+u_{s 3} \\
& =\left(\frac{1}{\alpha}-1\right) u_{B}+u_{s 2}+u_{s 3} \\
& =\left(\frac{1}{\alpha}-1\right)\left\{u_{B y}+\frac{P-P_{y}}{P_{u}-P_{y}}\left(u_{B u}-u_{B y}\right)\right\} \\
& +u_{s 2}+u_{s 3}
\end{aligned}
$$

\section{Hysteretic Model}

The Takeda model (6) seems to be suitable for the hysteretic load versus flexural deformation relationship.

One of possible representations for the hysteretic load versus shear deformation relationship may be the Shina model (7) which was proposed by $M$ A Sozen et al for the members including pinching phenomena. Figures 18 and 19 show these hysteretic relationships.

\section{CONCLUSIONS} reached:

The following conclusions have been

1. Shear deformation is overestimated, and consequently flexural deformation is underestimated if the shear deformation is determined simply as a difference in length of two diagonals.

2. Flexural and shear deformations are estimated with excellent accuracy by using the rotation at the storey midheight of a shear wall.

3. Shear deformation increases by the rotational mechanism having a rotation centre at the base of the column under compression.

4. Shear deformation significantly increases after reinforcing bars of the boundary column under tension yield. The ratio of the shear deformation to the flexural deformation is analytically determined by a truss model which has a non-prismatic member.

\section{ACKNOWLEDGEMENTS}

This study was carried out while the writer visited the Construction Technology Laboratories, Portland Cement Association, Skokie, Illinois. The writer is indebted to $\mathrm{Dr}$ M Watabe of BRI and Dr W G Corley of PCA for their significant efforts to his visiting PCA, and to Mr R G Oesterle of PCA, for - providing references and advice. The writer also expresses his appreciation to Professor M Tomii of Kyushu University for his advice and encouragement. The writer wishes to thank Miss M Sakairi who typed the manuscript.

\section{REFERENCES}

(1) R G Oesterle, A E Fiorato, L S Johal, $J$ E Carpenter, $H$ G Russeli and $W$ G Coley, "Earthquake Resistant Structural Walls - Tests of Isolated Walls", Report to National Science Foundation, Portland Cement Association, Skokie, November 1976.

(2) H Bachmann, "Influence of Shear and Bond on Rotational Capacity of Reinforced Concrete Beams", Publications, International Association for Bridge and Structural Engineering, Vol 30, Part II, Zurich, 1970, pp $11-28$.

(3) S Nakata, K Shimazaki, H Tsubozaki and R Nitta, "US-Japan Cooperative Research Program (Study on the Full- 


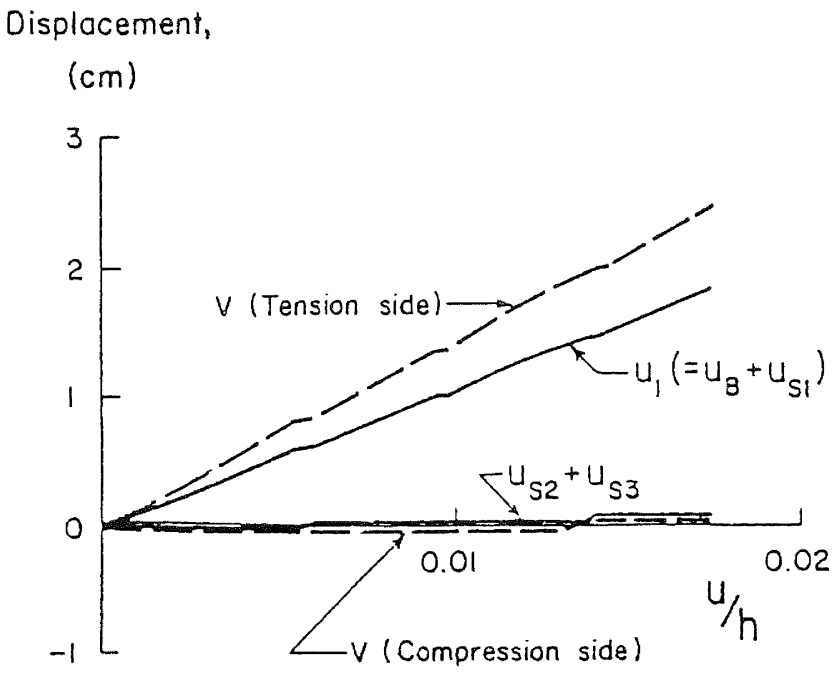

Fig. 11 Relationship of $u / h$ versus Each Horizontal Displacement and Each Vertical Displacement of the Columns at the Top of the First Story

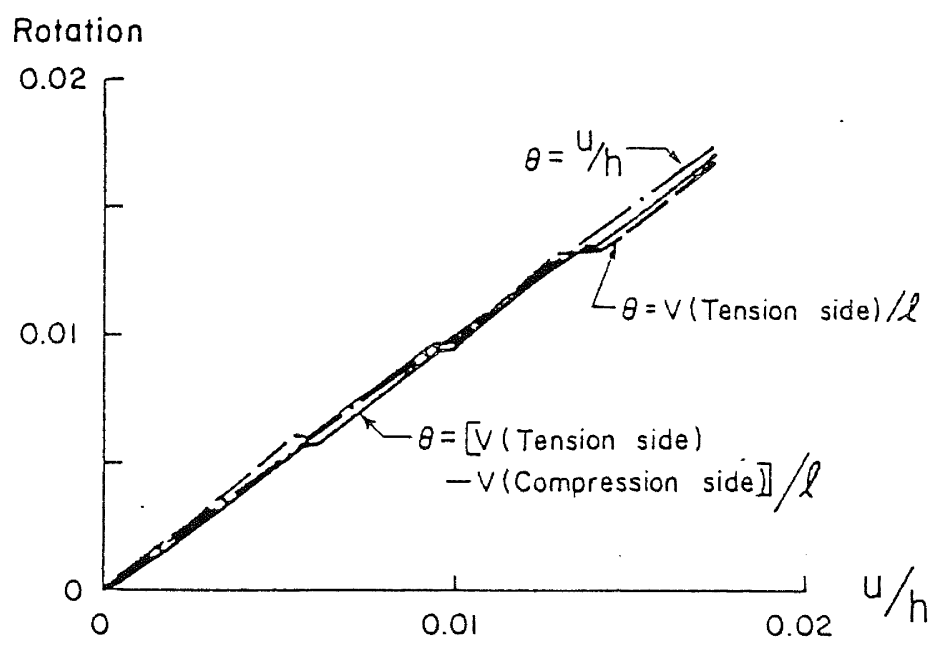

Fig. 12 Relationship of $\mathrm{u} / \mathrm{h}$ versus Relation at Iop of First Story

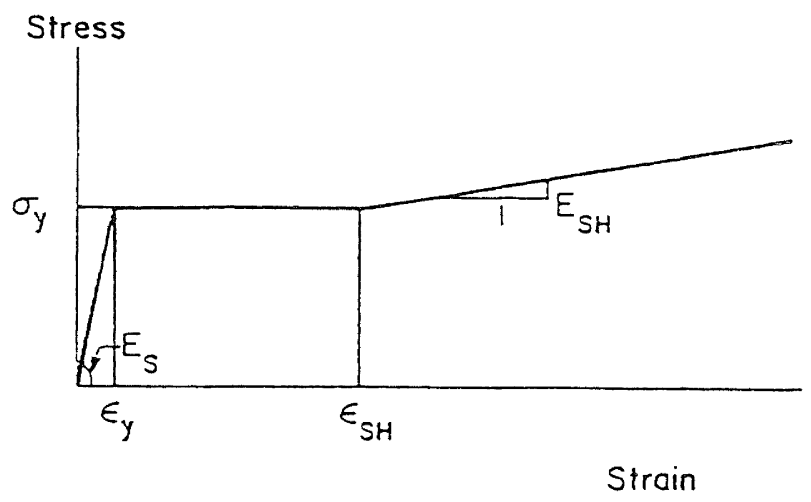

Fig. 13 Assumed Stress versus Strain Relationship for Steel 
Scale Seismic Experiment of a Seven Story Reinforced Concrete Building Part I)", AIJ Annual Meeting, September 1981, pp 1263-1264.

(4) H Hiraishi, M Yoshimura, H Isoishi and S Nakata, "US-Japan Cooperative Research Program Utilizing Large-Scale Testing Facilities. Part IV", AIJ Annual Meeting, September 1980, pp 1661-1662.

(5) B J Morgan, H Hiraishi and W G. Corley, "Tests of Planar Wall Assemblies under In-Plane Static Reversing Loads", Portland Cement Association, Skokie, Serial No 1703, July 1982.

(6) T Takeda, M A Sozen and N N Nielsen, "Reinforced Concrete Response to Simulated Earthquakes", Journal of the Structural Division, ASCE, Vol 96, No ST12, Proc. Paper 7759, December 1970, pp 2557-2573.

(7) M Saiidi and M A Sozen, "Simple and Complex Model For Nonlinear Seismic Response of Reinforced Concrete Structures", Civil Engineering Studies, Structural Research Series No 465, University of Illinois

- Urbana, ILL., August 1979, pp 27-29.

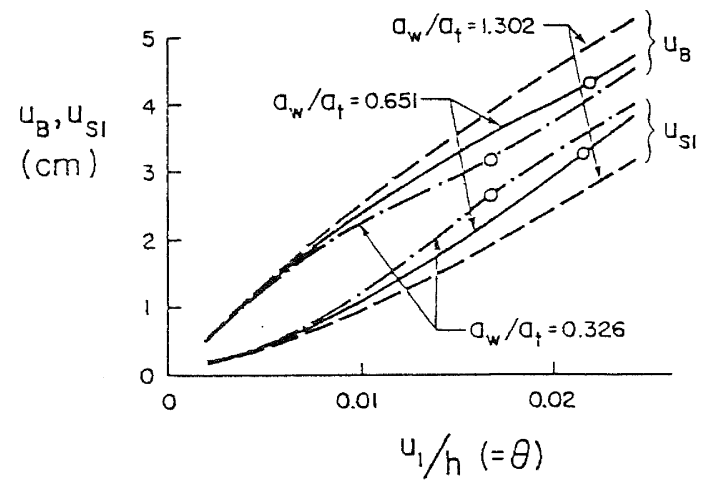

Fig. 14 Calculated Relationship of $\mathrm{u}_{1} / \mathrm{h}$ versus $\mathrm{u}_{\mathrm{B}}, \mathrm{u}_{\mathrm{S}_{1}}$

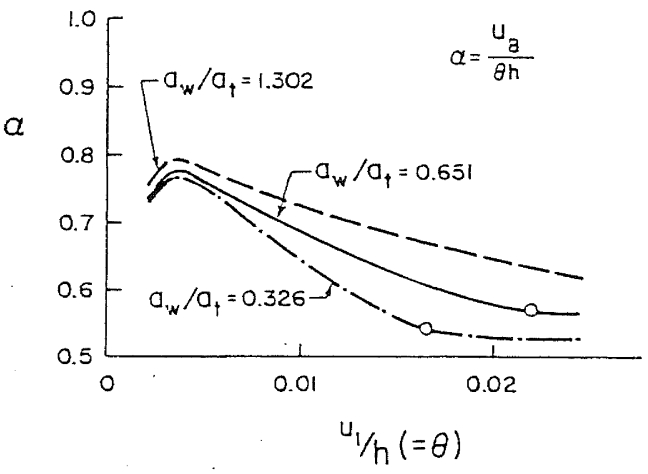

Fig. 15 Calculated Relationship of $u_{1} / \mathrm{h}$ versus $\alpha$

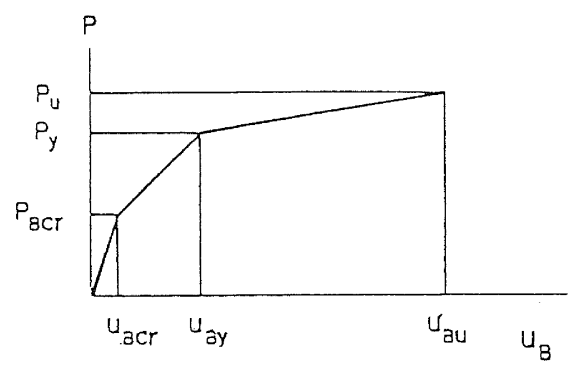

Fig. 16 Idealized Load versus Flexural Deformation Relationship

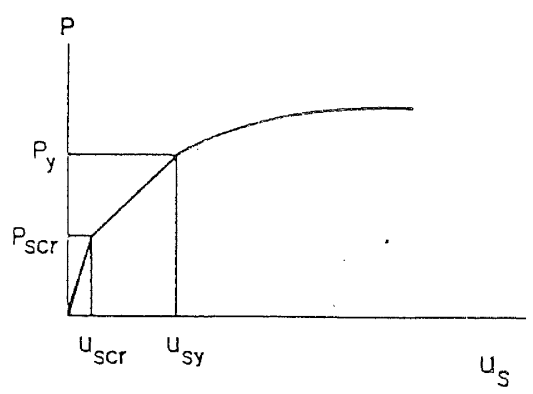

Fig. 17 Idealized Load versus Shear Deformation Relationship

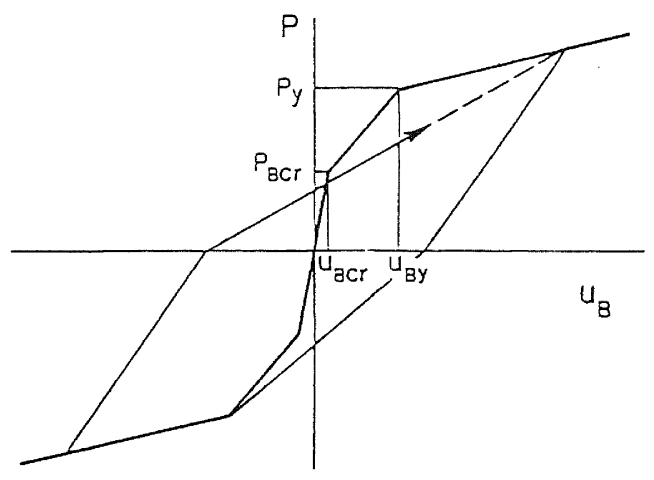

Fig. 18 Hysteresis Load Versus Flexural Deformaiton Model

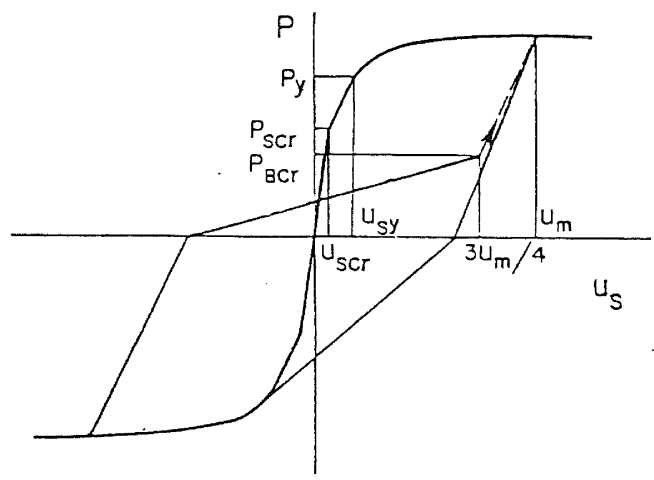

Fig. 19 Hysteresis Load versus Shear Deformation Model 